\section{Estimation of digestible energy in horse diets using an in vitro method}

\author{
Annette Zeyner and Armin Dittricht \\ Institute of Animal Nutrition, Nutritional Diseases and Dietetics, University of \\ Leipzig, Germany
}

\section{Introduction}

The content of digestible energy (DE) in horse feed can be estimated, on principal, by regression equations based on chemical-analytical parameters of the feed (Zeyner 1995, Zeyner and Kienzle 2002) or patterns of simulated digestion (Applegate and Hershberger 1969, Sunvold et al. 1995, Macheboeuf and Jestin 1997, Macheboeuf et al. 1997, Lowman et al. 1999, Moore-Colyer and Longland 2000, MooreColyer et al. 2003, Murray et al. 2003, Hayes et al. 2003, Lattimer et al. 2005, Ringler et al. 2005ab, Turcott et al. 2005, Warren and Kivipelto 2005). As to the latter, a method that exists in slight variations works by incubation with pepsin and cellulase. Until know it is successfully used to estimate the amount of digestible organic matter in forages for ruminants (Nousiainen et al. 2003), but has never been tested to value horse feed. This study was conducted to prove the fitness of in vivo determined pepsin-cellulase indigestible organic matter (OMid) to estimate the DE content of horse diets with a comparably high variation in fibre content and quality while in vivo results act as control.

\section{Material and methods}

Nine digestion trials with fife adult horses were conducted to determine the DE content of diets composed of oats, maize, grass hay and straw, respectively, in vivo (Zeyner et al. 1992). The proximate nutrients varied as follows (in \% of the dry matter, DM): crude ash, 3.0-8.8; crude protein, 6.3-12.3; acid ether extract, 2.7-3.4; crude fibre, 17.9-27.8; nitrogen free extract, 44.4-67.9; neutral detergent fibre (NDF), 38.853.3; acid detergent fibre (ADF), 21.3-36.4; acid detergent lignin (ADL), 2.4-5.6. Between 10.2 and $16.5 \%$ of the ADF were found to be ADL. For in vitro investigations, the pepsincellulase method by Nehring (1979) in a modification according to Friedel (1990) was used to measure the amount of OMid in the feed. The qualification of in vitro OMid alone or in touch with different nutrient fractions was proved to estimate the DE content of the diets regressively by use of SPSS 11.0 (SPSS Inc., Chicago, Illinois, USA).

\section{Results}

In vivo DE as well as in vivo and in vitro OMid in the DM of the diets varied from 10.1 to $13.5 \mathrm{MJ}$ as well as 203 to 438 and 126 to $397 \mathrm{~g}$, respectively. In this way, mean in vitro OMid was clearly lower than the parallel in vivo result. Nevertheless, in vivo and in vitro OMid were highly linearly related (Fig. 1). The slope of the regression equation to estimate in vivo from in vitro OMid lied below 1 in the manner that the difference between results from both methods was the higher the lower the OMid was. The DE content ( $y$, in MJ/kg DM) was valuable from in vitro OMid $\left(x_{1}\right.$, in $\left.\mathrm{g} / \mathrm{kg} \mathrm{DM}\right)$ by the following equation: $y=14.79-0.013 x_{1}\left(R^{2}=0.810, P<0.001\right)$. The mean difference between the measured and regressively estimated energy content $(|\Delta|)$ amounted to $0.45 \pm 0.35 \mathrm{MJ}$ $\mathrm{DE} / \mathrm{kg} \mathrm{DM}$. The best estimation could be obtained by further inclusion of the cell content (CC) of the feed $\left(x_{2}\right.$, in $\left.\mathrm{g} / \mathrm{kg} \mathrm{DM}\right)$ as independent factor which was defined as organic matter minus NDF (Zeyner 1995): $y=12.50-0.012 x_{1}+0.004 x_{2}$ $\left(R^{2}=0.882, P<0.001\right)$. In this way, $|\Delta|$ was reduced to $0.39 \pm 0.34 \mathrm{MJ} D E / \mathrm{kg}$ DM.

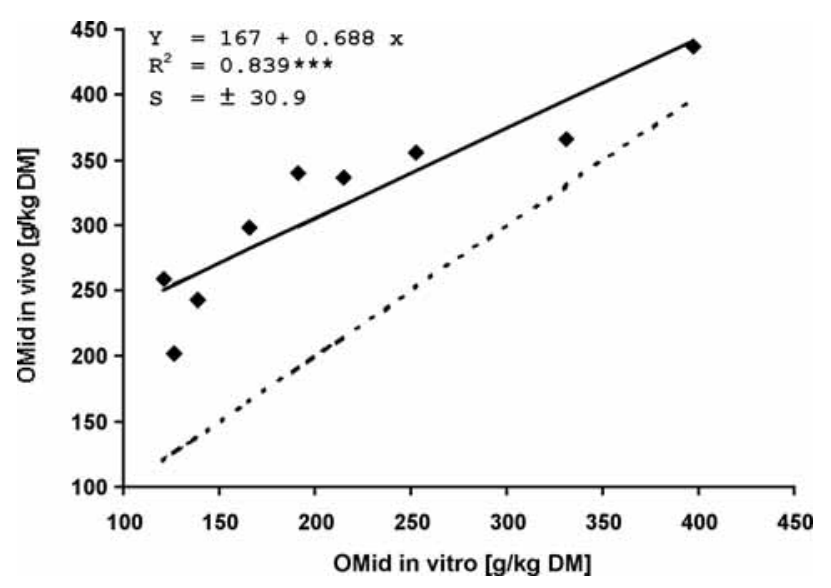

Fig 1 Relation between the content of in vivo and in vitro determined indigestible organic matter (OMid) in the experimental diets.

\section{Discussion}

In the recent study, the number of experimental diets available to compare in vivo and in vitro results was clearly limited, but the chosen diets were highly variable regarding the content of fibre and it's quality, measured as degree of lignification. The content of highly digestible nutrients, except fat, varied notably too. Within this inhomogenous material, pepsin-cellulase OMid allowed, on principle, to create acceptable regression equations to estimate the DE content of the diets. However, in vivo and in vitro OMid were linearly but not strongly parallel related and therefore in vitro OMid and in vivo $D E$, too. This may be why the digestibility of soluble carbohydrates as a main part of the CC can not be covered by the pepsin-cellulase method. This causes the need for a correction, particularly for diets with a low content of OMid which are in most cases especially high in CC. Fortunately, the digestible fraction of CC depends linearly positively from the dietary CC content itself (Zeyner 1995). Thus, a regression equation to estimate the dietary DE content that additionally includes CC as independent factor fits better. Based on the in vitro applied enzymes, the application of such an equation is strongly limited to diets with native amounts of fat. 


\section{Conclusions}

In vitro determined OMid in the feed seems to be suitable to estimate the DE content of diets with native fat contents regressively. The further inclusion of the dietary CC content as independent factor increases the security of the target function.

\section{References}

Applegate C. S. and Hershberger T. V. (1969): Evaluation of in vitro and in vivo caecal fermentation techniques for estimating the nutritive value of forages for equine. Journal of Animal Science $28,18-22$

Friedel K. (1990): Estimation of the energy feeding value of roughages with a cellulase method (in German). Wissenschaftliche Zeitschrift Universität Rostock. Naturwissenschaftliche Reihe 39, 78-86

Hayes S., Werner H. and Lawrence L. (2003): In vitro assessment of fiber digestion capacity in foals. Proceedings of the 18th Symposium of the Equine Nutrition and Physiology Society, May 04-07, East Lansing, USA, 273-274

Lattimer J. M., Cooper S. R., Freeman D. W. and Lalman D. A. (2005): Effects of Sacchoromyces cerevisiae on in vitro fermentation of a high concentrate or high fibre diet in horses. Proceedings of the 19th Symposium of the Equine Science Society, May 31 Jun 03, Tucson, USA, 168-173

Lowman R. S., Theodorou M. K., Hyslop J. J., Dhanoa M. S. and Cuddeford D. (1999): Evaluation of an in vitro batch culture technique for estimating the in vivo digestibility and digestible energy content of equine feeds using equine faeces as the source of microbial inoculum. Animal Feed Science Technology 80, 1 1-27

Macheboeuf D. and Jestin M. (1997): Utilization of the gas test method using horse faeces as a source of inoculum. Proceedings of the International Symposium 'In vitro Techniques for Measuring Nutrient Supply to Ruminants', Jul 8-10, Whiteknights, Reading, UK, 36

Macheboeuf D., Jestin M., Andrieu J. and Martin-Rosset W. (1997): Prediction of the organic matter digestibility of forages in horses by the gas test method. Proceedings of the International Symposium 'In vitro Techniques for Measuring Nutrient Supply to Ruminants', Jul 8-10, Whiteknights, Reading, UK, 59

Moore-Colyer M. J. S. and Longland A. C. (2000): In vivo apparent digestibility of four types of conserved forage by ponies. Animal Science 71, 527-534

Moore-Colyer M. J. S., Longland A. C. and Murray J. (2003): Microbial activity and degradation capacity in nine regions of the equid gut using the gas production technique. Proceedings of the 18th Symposium of the Equine Nutrition and Physiology Society, May 04-07, East Lansing, USA, 118-120

Murray J. M. D., Longland A. C., Moore-Colyer M. J. S. and Dunnett C. (2003): The effect of diet and donor animal on the fermentative capacity of equine faecal inocula for use in in vitro digestibility determinations. Proceedings of the 18th Symposium of the Equine Nutrition and Physiology Society, May 04-07, East Lansing, USA, 121-123
Nehring K. (1979): Die Ermittlung des Futterwertes. Archives Animal Nutrition 29, $311-337$

Nousiainen J., Rinne M., Hellämäki M. and Huhtanen P. (2003): Prediction of the digestibility of the primary growth of grass silages harvested at different stages of maturity from chemical composition and pepsin-cellulase solubility. Animal Feed Science Technology 103, 97-111

Ringler J., Cassill B., Hayes S. and Lawrence L. (2005a): Comparison of in vitro digestibility estimates using the Daisy II incubator to in vivo digestibility estimates. Proceedings of the 19th Symposium of the Equine Science Society, May 31 - Jun 03, Tucson, USA, 4344

Ringler J., Cassill B., Hayes S. and Lawrence L. (2005b): Effect of incubation time on in vitro estimates of DM, NDF, and ADF digestibility obtained using equine feces as inoculum. Proceedings of the 19th Symposium of the Equine Science Society, May 31 - Jun 03, Tucson, USA, 307-308

Sunvold G. D., Hussein H. S., Fahey G. C., Merchen N. R. and Reinhart G. A. (1995): In vitro fermentation of cellulose, beet pulp, citrus pulp, and citrus pectin using fecal inoculum from cats, dogs, horses, humans, and pigs and ruminal fluid from cattle. Journal of Animal Science 73, 3639-3648

Turcott S. K., Nielsen B. D., O'Connor C. I., Hengemuehle S. M. and Yokoyama M. T. (2005): Estimation of total numbers and presumptive identification of cellulolytic bacteria in cecal contents of the adult horse. Proceedings of the 19th Symposium of the Equine Science Society, May 31 - Jun 03, Tucson, USA, 354-359

Warren L. K. and Kivipelto J. (2005): Comparison of cecal or fecal inocula used in the determination of in vitro fiber digestibility. Proceedings of the 19th Symposium of the Equine Science Society, May 31 - Jun 03, Tucson, USA, 168-173

Zeyner A. (1995): Ermittlung des Gehaltes an verdaulicher Energie im Pferdefutter über die Verdaulichkeitsschätzung. Übersichten Tierernährung 23, 55-104

Zeyner A., Hoffmann M. and Fuchs R. (1992): Possibilities of computation of the content of digestible energy in diets for riding horses (in German). Pferdeheilkunde, Sonderausgabe 175-178

Zeyner A. and Kienzle E. A. (2002): Method to estimate digestible energy in horse feed. Journal of Nutrition 132, 1771S-1773S

\section{A. Zeyner}

Institute of Animal Nutrition, Nutritional Diseases and Dietetics,

University of Leipzig

Gustav-Kühn-Str. 8

04159 Leipzig

Germany

zeyner@vetmed.uni-leipzig.de 